\title{
Philtral Columns and Nostril Shapes in Nigerian Children: A Morphometric and Aesthetic Analysis
}

\author{
Ibrahim Abdulrasheed and Asuku Malachy Eneye \\ Division of Plastic Surgery, Department of Surgery, Ahmadu Bello University Teaching Hospital, P.O. Box 06, Shika, \\ Kaduna State, Zaria 810001, Nigeria
}

Correspondence should be addressed to Ibrahim Abdulrasheed; shidoibrahim@yahoo.com

Received 1 April 2013; Accepted 26 May 2013

Academic Editor: Francesco Carinci

Copyright ( 2013 I. Abdulrasheed and A. M. Eneye. This is an open access article distributed under the Creative Commons Attribution License, which permits unrestricted use, distribution, and reproduction in any medium, provided the original work is properly cited.

\begin{abstract}
Background. The upper lip-nose complex contributes significantly to the concept of symmetry and proportion of the face. A study of the morphology and aesthetic preferences of the lip-nose complex will provide a database that will serve as a guide for reconstruction. Subjects and Methods. Hundred Nigerian children participated in this study. Demographic data and standard photographs of the philtral column and nostrils were obtained. Sixty volunteers were recruited to evaluate the photographs. Each volunteer was asked to rank the photographs based on their aesthetic preference. Results. The morphology of the philtral columns was classified into four groups: (1) triangular, (2) concave, (3) flat, and (4) parallel. The nostril shape was also classified into four groups: (1) triangular, (2) round, (3) teardrop, and (4) rectangular. In both genders, the triangular shape of philtral column was the most common. There are significant age differences in the aesthetic rankings of philtral columns and nostril shapes. Conclusion. Our study establishes the basal values for the morphometric and aesthetic parameters of the lip-nose complex of 5- and 6-year-old children in Nigeria. We hope our results and reconstructive surgery will intersect at a point to treat disfigurements of the philtrum and nostrils successfully.
\end{abstract}

\section{Introduction}

The human face is one of the most attractive parts of the body [1]. It is central to many aspects of social interaction and the visual perception of the face is influenced by a complex combination of various factors such as appearance, expression, and symmetry. Earlier reports $[2,3]$ have shown that there is a proportional relationship between symmetry and attractiveness, and symmetrical faces are generally perceived as more attractive.

The upper lip-nose complex is an important aesthetic facial unit. It contributes significantly to the concept of symmetry, harmony, and proportion of the face $[1,4]$. The philtrum is the central unit of the upper lip and plays a key role in the appearance of the lip and nostril $[5,6]$. It consists of the dimple, two philtral ridges, the tubercle, and the white roll between the two high points of Cupid's bow. The philtrum is especially prominent during conversation and facial expression [7]. During labial movement, a dimple is formed, with accentuation of the philtral ridges [5]. The nose is located in the middle of the face and is the most defining feature. Thus, it naturally attracts the gaze of the onlooker $[4,8]$. The shape of the nostril is a signature indicating the ethnicity, race, age, and sex [9]. Given its importance and ability to change the appearance of the face, asymmetry of the nostrils will affect overall facial appearance $[2,10]$. It is, however, also well recognized that disfigurements of the philtral columns and nostrils from congenital and acquired deformities causes significant emotional distress. This is because any deformity of the face has always been considered as one of the least desirable handicaps $[3,11]$.

Research provides evidence that the study of the morphology of the Lip-nose complex at various ages serves as a guideline for reconstruction [12-15]. Corresponding studies in Nigeria are very scarce. Furthermore, popular views of aesthetics of the face continue to evolve as our communities become more diverse and as the media and popular culture increasingly influence our tastes. A thorough 
understanding of current societal preferences will help guide surgical planning for aesthetic surgery of the face [16]. The purpose of this study is thus twofold: (1) to establish the morphology of philtral columns and nostril shape in Nigerian children, and (2) to identify the aesthetic preferences of philtral column and nostril shape in Nigerian children.

\section{Subjects and Method}

2.1. Morphology of Philtral Column and Nostrils. Subjects included in this study were required to be 5 or 6 years of age and both parents to be of Nigerian heritage. There were 100 Nigerian children (54 males, 46 females). The boys were aged 6 years ( 24 children) and 5 years ( 30 children) and the girls were aged 6 years (22 children) and 5 years (24 children). Other inclusion criteria included no history of craniofacial syndromes, major trauma, or previous plastic and reconstructive surgery of the face. We analyzed the shape of the philtral columns and nostrils and classified it into four groups. These groups are similar to those described by Mori et al. [13] Figure 1. Figure 1(a) triangular type: the origins of the philtral column are located near both sides of the medial crural footplates. The philtral dimple is approximately triangular. Figure 1(b) parallel type: the philtral columns originate from the nostril sills and exhibit an almost parallel shape with a prominent dimple along the upper lip. Figure 1(c) concave type: the philtral columns begin in the lower half of the upper lip and the dimple is emphasized. There is no philtrum dimple in the upper half of the upper lip. Figure 1(d) flat type: the philtral columns have almost no prominence with a vaguely delineated dimple. The nostril shapes were classified into four groups: Figure 2(a) round type, Figure 2(b) rectangular type, Figure 2(c) teardrop type, and Figure 2(d) triangular type (Figure 2).

Statistical evaluation of data was performed on SPSS 17.0 (SPSS Inc., Chicago, IL) statistical package program for Windows. Age and sex differences were evaluated using $t$-test and $P<0.05$ was considered to be statistically significant.

2.2. Aesthetic Preferences of Philtral Column and Nostril Shape. Photographs of the philtral columns and nostril shape were obtained by the primary author (A.I.). Photographs were taken with a Canon IXUS 130 digital camera, 14.1 megapixels. (Canon United Kingdom). We took pictures of the philtrum and the upper lip in frontal view. The children had their head bent back, vertically exposing the nostrils. From this position, photographs of the nostril shape were obtained. We selected four photographs each, of the shape of the philtral columns and nostrils (Figures 3 and 4). The photographs were then placed onto two PowerPoint slides for viewing. We subsequently recruited 60 volunteers (30 professionals and 30 laypersons) to evaluate the photographs. The professionals consisted of consultant plastic surgeons, surgery residents, and nurses. The laypersons included members of the office staff of the department of surgery, friends, and relatives of patients at the surgical outpatient department. Each volunteer was asked to rank the photographs of the shape of the philtral column and nostril shape based on their aesthetic preference.
They were directed to rate each on a scale from 1 to 5 , with 1 representing "very unattractive" and 5 as "very attractive."

On the basis of age, volunteers were divided into 2 groups: 35 years or older and younger than 35 years. Using MannWhitney tests, statistical comparisons based on volunteer age, sex, and profession were completed. $P<0.05$ was considered as statistically significant.

\section{Results}

3.1. Morphology of Philtral Column and Nostrils. In both genders, the triangular type was the most common, and the parallel type was the second most common. The distribution of participants into groups regarding sex was not significantly different in the triangular group compared with the parallel, concave, and flat groups $(P=0.207)$. The result of the classification of the shape of the philtral column is shown in Table 1 .

The teardrop-shaped nostrils were more common than the other types (Table 2). Triangular shaped nostril was the commonest in male while the teardrop shaped nostril was the commonest in females. This distribution was, however, not statistically significant, $P=0.690$.

3.2. Aesthetic Preferences of Philtral Column and Nostril Shape. The professionals ranked the flat and parallel philtral columns higher while the laypersons scored the triangular and concave philtral columns more favorably. However, these differences are not statistically significant (Table 3 ). The distinction in the rankings between female and male volunteers was also less clear. Compared with females, males prefer the parallel and triangular shaped philtral column, whereas females ranked the flat and concave philtral shaped columns higher. This trend was also not statistically significant. The only statistically significant ranking was based on volunteer age, with volunteers less than 35 years preferring the concave shaped philtral column.

For nostril shape, the mean scores the professionals were slightly higher than the laypersons (Table 4 ). The mean scores for the professionals ranged 28.25-35.35 while the mean scores for the laypersons ranged 25.65-32.75. The aesthetic ranking of the triangular shaped nostril was statistically significant. $P=0.025$ between the two groups. Comparisons of rating scores between male and female volunteers revealed higher mean scores by females (Females 30.56-31.08 versus Males 29.88-30.43). This distribution did not show a statistically significant difference. When comparing the aesthetic ratings of volunteers less than 35 years and those older than 35 years, the mean scores in the triangular and round shaped nostrils were statistically significant $(P=0.015$ and $P=$ 0.025).

\section{Discussion}

Objective evaluation of the face is based on measurements, proportions, and shapes. A great body of work in facial anthropometry is that of Farkas, who established a database of norms that are well accepted as linear, angular, and surface 


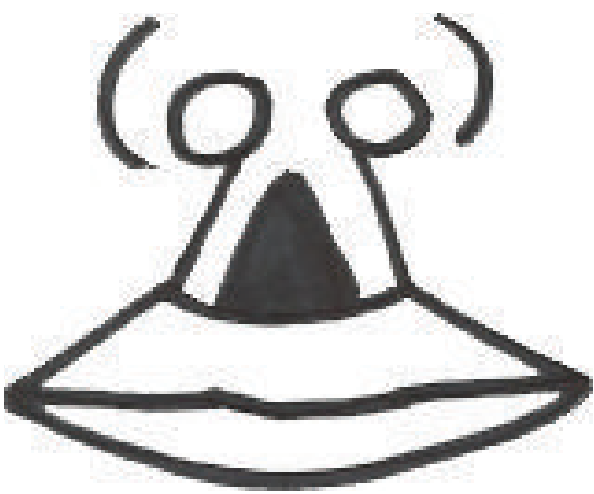

(a)

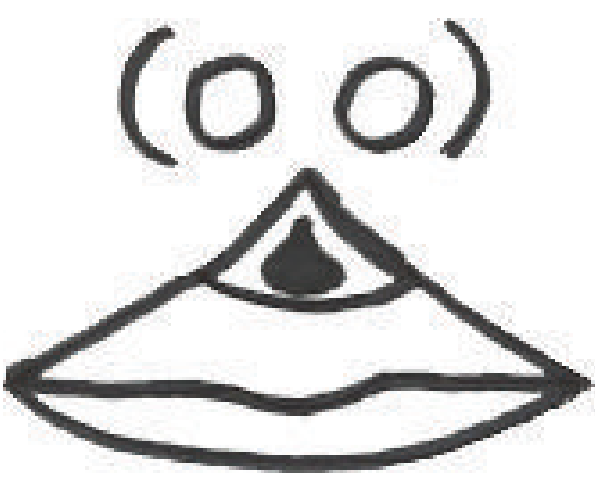

(c)

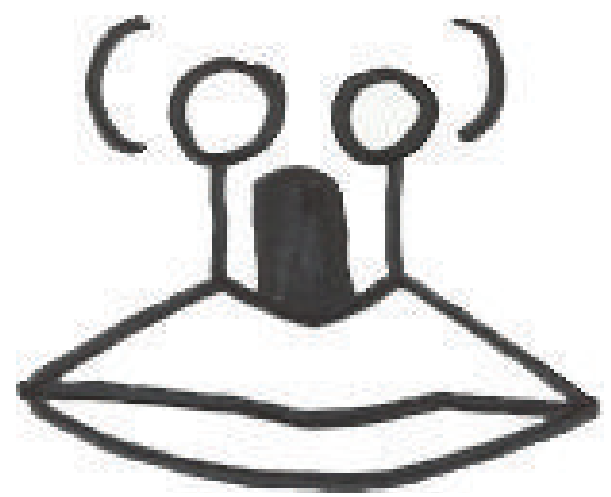

(b)
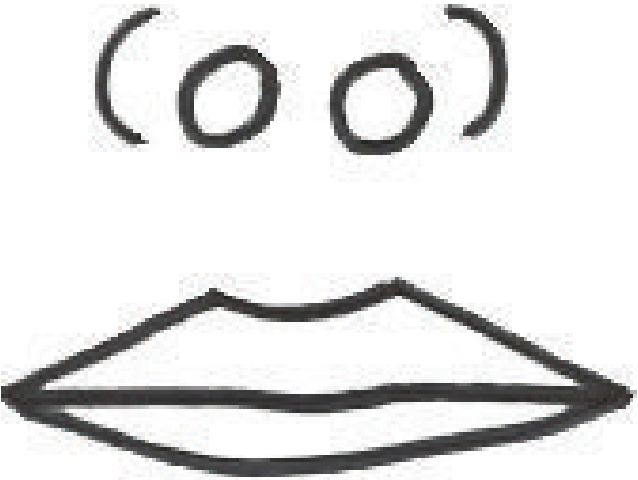

(d)

FIGURE 1: Diagram of philtral shape classification, Mori et al. [13]. (a) Triangular type, (b) parallel type, (c) concave type, and (d) flat type.

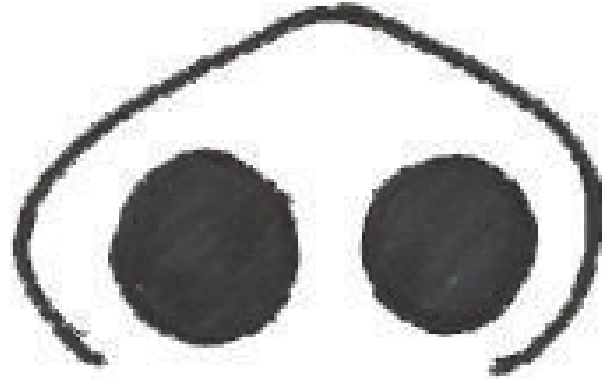

(a)

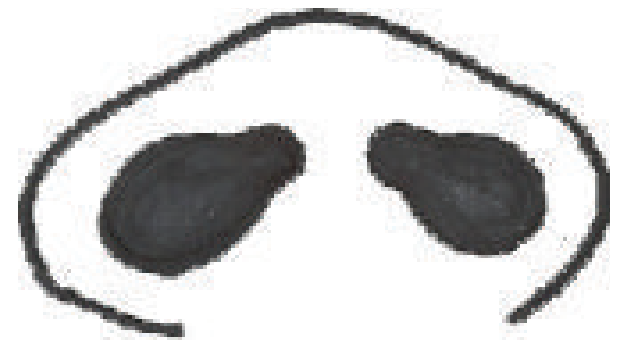

(c)

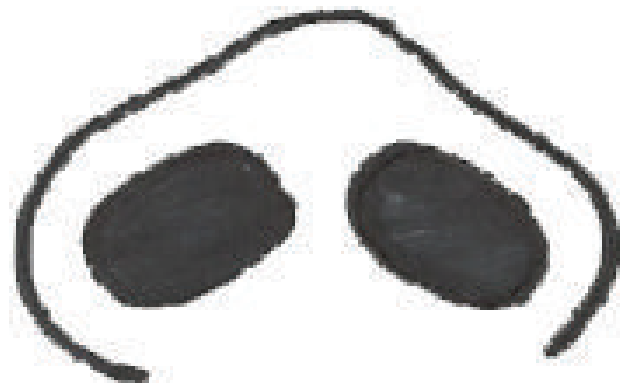

(b)

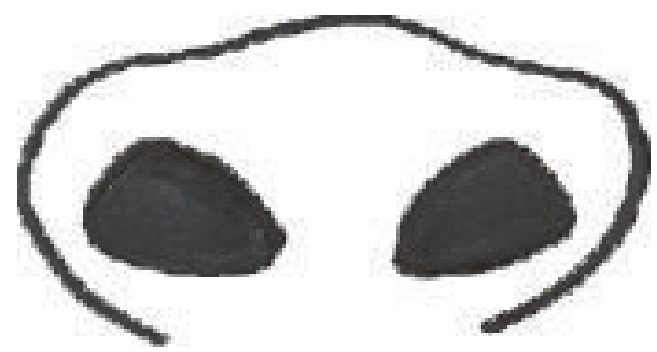

(d)

FIgURE 2: Diagram of nostril shape classification. (a) Round type, (b) rectangular type, (c) teardrop type, and (d) Triangular type. 


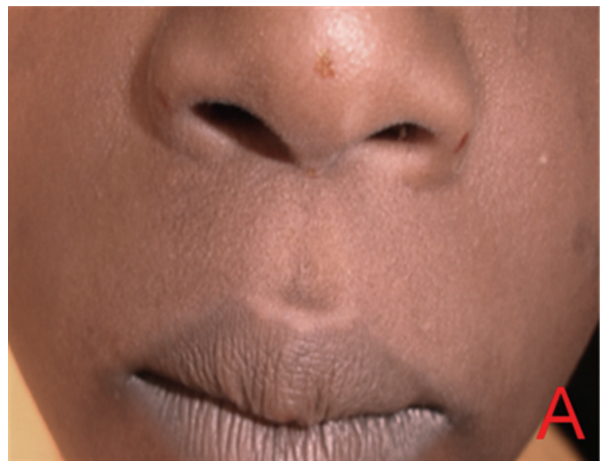

(a)

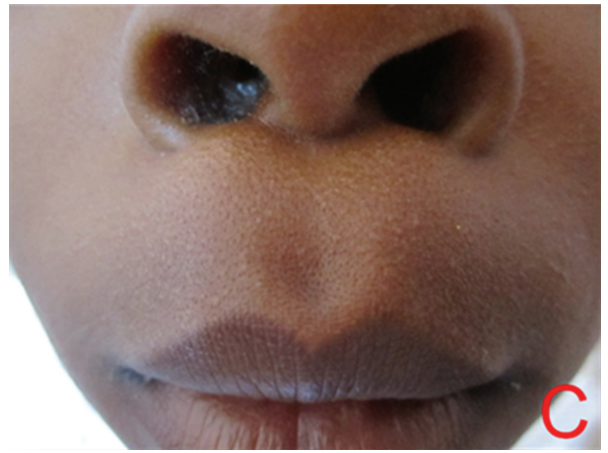

(c)

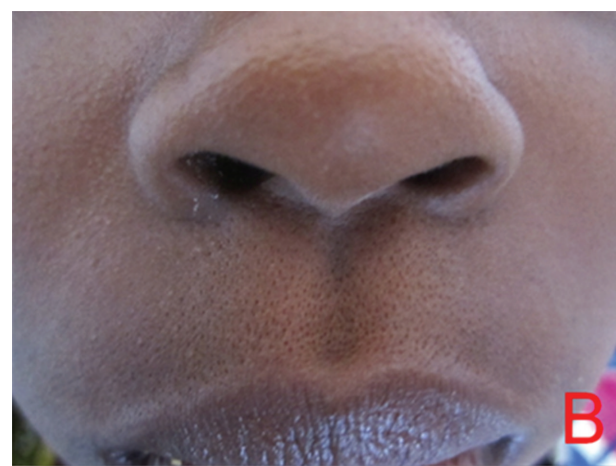

(b)

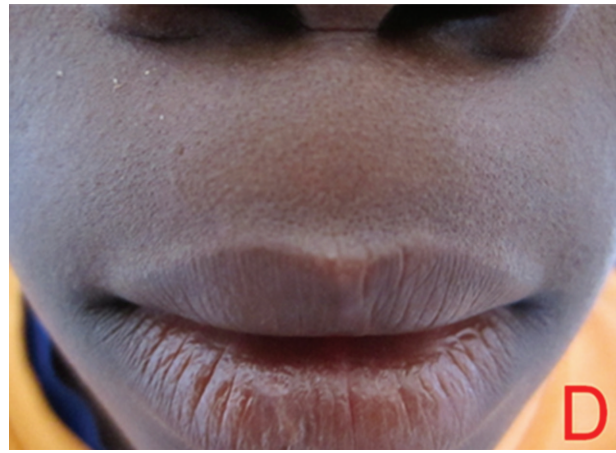

(d)

FIgURE 3: Pictures of philtral shape classification [13]. (a) Triangular type, (b) parallel type, (c) concave type, and (d) flat type.

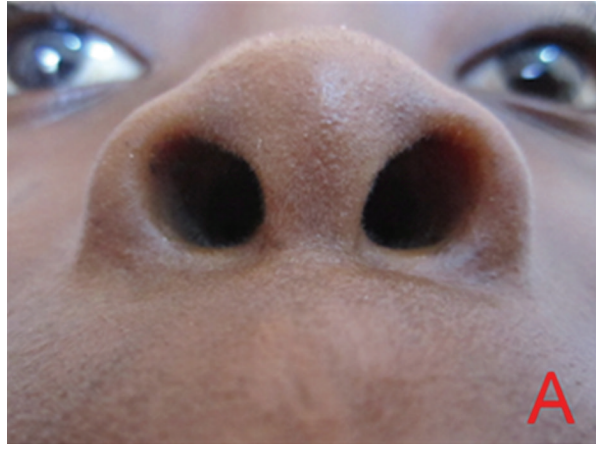

(a)

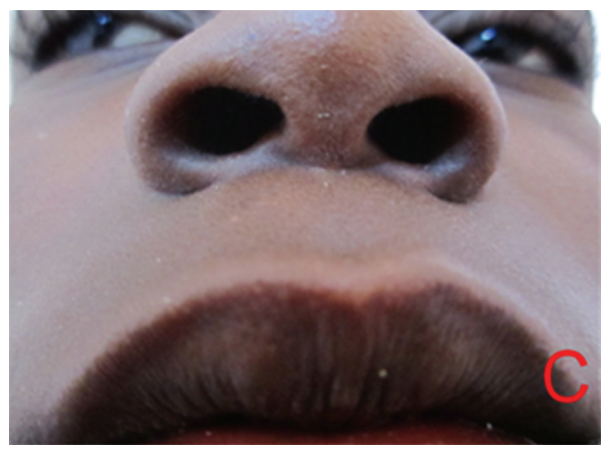

(c)

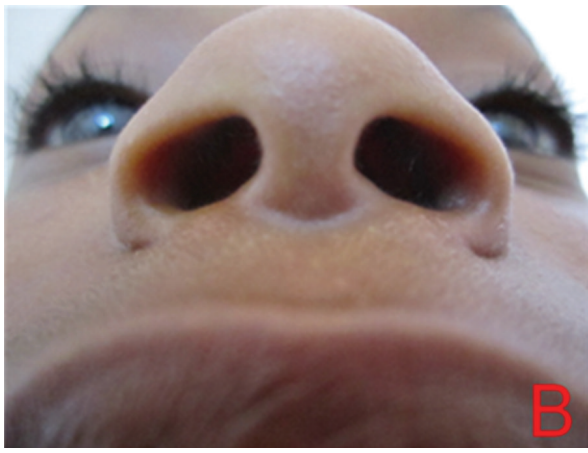

(b)

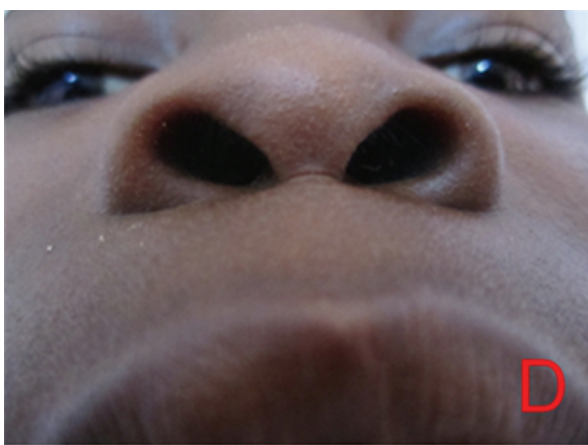

(d)

FIgURE 4: Pictures of nostril shape classification. (a) Round type, (b) rectangular type, (c) teardrop type, and (d) triangular type. 
TABLE 1: The distribution of participants related to their sex and shape of philtral column.

\begin{tabular}{lccccc}
\hline \multirow{2}{*}{ Shape of philtrum } & Total & \multicolumn{2}{c}{ Male } & \multicolumn{2}{c}{ Female } \\
& $N$ & $N$ & $\%$ & $N$ & $\%$ \\
\hline Parallel & 19 & 8 & 42.1 & 11 & 57.9 \\
Triangular & 55 & 34 & 61.8 & 21 & 38.2 \\
Concave & 12 & 4 & 33.3 & 8 & 66.7 \\
Flat & 14 & 8 & 57.1 & 6 & 42.9 \\
\hline Total & 100 & 54 & & 46 & 100 \\
\hline
\end{tabular}

TABLE 2: The distribution of participants related to their sex and shape of the nostrils.

\begin{tabular}{lccccc}
\hline \multirow{2}{*}{ Shape of nostril } & Total & \multicolumn{2}{c}{ Male } & \multicolumn{2}{c}{ Female } \\
& $N$ & $N$ & $\%$ & $N$ & $\%$ \\
\hline Triangular & 39 & 23 & 59 & 16 & 41 \\
Round & 13 & 7 & 53.8 & 6 & 46.2 \\
Teardrop & 42 & 22 & 52.4 & 20 & 47.6 \\
Rectangular & 6 & 2 & 33.3 & 4 & 66.7 \\
\hline Total & 100 & 54 & & 46 & \\
\hline
\end{tabular}

contour reference values $[9,17]$. Other reference values are from $2 \mathrm{D}$ cephalometric and photographic assessments [13, 18-21]. More recently, the laser scanning technique, the contact-type 3-dimensional measurement technique using facial plaster models, and the measurement technique using 3-dimensional computed tomography are considered to be able to 3 - dimensionally measure the complicated shape of the face and to produce images on a computer screen [13,20,22].

The analysis obtained in this study was based on twodimensional basal views and photographs of the philtral columns and the nostrils because they were economical, convenient, and noninvasive. Photographs were chosen to assess aesthetic preferences because they were proven to be reliable in previous studies $[23,24]$. The strengths and limitations of photographic assessments must be appreciated. It is sensitive to the angle from which the photograph is taken and the position of the head. Because photographs are taken from varying distances with lenses of different focal lengths, the magnification of the final image is unknown. Therefore, it is unsuitable for absolute measurements, unless standardized procedures are followed to ensure a consistent, known magnification. However, it is ideally suited to the evaluation of proportions and shapes, as the magnification factor is eliminated [15].

The morphology of the philtral columns was classified into four types for Japanese children by Mori et al. in 2005 [13]. Amongst Nigerian children, in both genders, the triangular type was the most common, and the parallel type was the second most common. This contrasts the findings in Japanese children where the parallel type was the most common in both genders, and the triangular type was the second most common [13]. This corroborates the distinct differences in facial morphology further emphasizing the need for separate standards for facial analysis.
The characteristics and differences of the shapes of the nostrils have been studied in several racial groups [13$15,18,21,25,26]$. Among the classifications of nostrils, Farkas' classification divides the shape of nostrils by the angle between the right and left long nostril axes [25]. We used 4 main nostril forms based on Farkas classification in an earlier report [15] and replaced the heart shaped nostril with the rectangular shaped nostril in our classification. Our data was compared with Ofodile's data in African Americans [26], and the teardrop nostril was the commonest in both studies. However, the African American group also had a type III in females which accounted for $4 \%$. The type III nostril shape was not present in this study.

Although the trend in this study demonstrates that female volunteers prefer the concave philtrum and triangular shaped nostril compared with male volunteers, these differences were not statistically significant. Furthermore, no differences were seen between professionals and laypersons volunteers for philtral column shape. Although some volunteers in this study were friends and relatives of patients in the hospital, most were graduate school students, a factor which introduces bias based on advanced educational level and urban residence [16]. In this study, it was found that the nostril shapes had higher aesthetic scores compared to the philtral columns shape. Two explanations for this finding are possible. First, the subjects were asked to not smile for an accurate assessment of philtral column shape. Rating pleasant, smiling lips may have resulted in higher aesthetic scores; however, this would have come with a price of decreased accuracy in philtral column assessment with the introduction of teeth and altered labial proportions. Another reason is that perhaps the ratings on photographs that are cropped are generally not a skill familiar to the volunteers and it may influence the results [27]. The difference in rating demonstrates the variance in what is perceived as attractive. Aesthetic judgments are subjective and may vary over time. It is therefore difficult to measure. Clinicians should thus develop patient-centered treatment goals through awareness of the aesthetic preference of their society $[28,29]$. The acknowledgment of this is increasingly important in the modern era because our society continues to become more heterogeneous [16].

4.1. Clinical Correlates. Cleft lip and palate is one of the most common deformities of the upper lip-nose subunit in Nigeria [30]. One of the major goals of surgery is to improve the aesthetic appearance of the face and thereby improve the patient's social acceptability [4, 19, 31, 32]. Unfortunately, the nature of the unilateral and bilateral cleft lip and nasal deformity makes the asymmetry difficult to correct completely $[5,6,27,33-36]$. A considerable number of children following cleft lip/nose repair in our institution had triangular shaped nostrils while others had heart shaped nostrils. Heart shaped nostrils are conventionally considered to be a typical nostril shape following cleft lip surgeries [13]. We also observed that the reconstruction of the cleft lip deformity (unilateral and bilateral) using modification of Millard's rotation advancement technique resulted in a parallel shape philtral column. A key feature of humans 
TABLE 3: Mean scores of philtral column shape preferences based on volunteer professional status, sex, and age.

\begin{tabular}{|c|c|c|c|c|c|c|c|c|c|}
\hline \multirow{2}{*}{ Philtral column shape } & \multicolumn{2}{|c|}{ Professional status } & \multirow{2}{*}{$P$ value } & \multicolumn{2}{|c|}{ Sex } & \multirow{2}{*}{$P$ value } & \multicolumn{2}{|c|}{ Age } & \multirow{2}{*}{$P$ value } \\
\hline & $\mathrm{P}^{\star}$ & $\mathrm{L}^{\star}$ & & M & $\mathrm{F}$ & & $<35$ & $>35$ & \\
\hline Flat & 32.40 & 28.60 & 0.362 & 29.57 & 31.37 & 0.666 & 28.73 & 33.79 & 0.247 \\
\hline Parallel & 32.67 & 28.33 & 0.320 & 31.76 & 29.32 & 0.577 & 27.73 & 35.64 & 0.083 \\
\hline Triangular & 30.38 & 30.62 & 0.957 & 31.40 & 29.66 & 0.691 & 30.29 & 30.88 & 0.898 \\
\hline Concave & 27.40 & 33.60 & 0.153 & 28.17 & 32.68 & 0.299 & 33.95 & 24.10 & 0.030 \\
\hline
\end{tabular}

$\mathrm{P}^{\star}$ : professional; $\mathrm{L}^{\star}$ : layperson.

TABLE 4: Mean scores of nostril shape preferences based on volunteer professional status, sex, and age.

\begin{tabular}{|c|c|c|c|c|c|c|c|c|c|}
\hline \multirow{2}{*}{ Nostril shape } & \multicolumn{2}{|c|}{ Professional status } & \multirow{2}{*}{$P$ value } & \multicolumn{2}{|c|}{ Sex } & \multirow{2}{*}{$P$ value } & \multicolumn{2}{|c|}{ Age } & \multirow{2}{*}{$P$ value } \\
\hline & $\mathrm{P}^{\star}$ & $\mathrm{L}^{\star}$ & & M & $\mathrm{F}$ & & $<35$ & $>35$ & \\
\hline Triangular & 35.35 & 25.65 & 0.025 & 29.88 & 31.08 & 0.782 & 26.64 & 37.67 & 0.015 \\
\hline Rectangular & 30.38 & 30.62 & 0.956 & 30.43 & 30.56 & 0.975 & 30.13 & 31.19 & 0.809 \\
\hline Tear drop & 30.48 & 30.52 & 0.994 & 30.22 & 30.76 & 0.902 & 31.08 & 29.43 & 0.718 \\
\hline Round & 28.25 & 32.75 & 0.308 & 29.97 & 31.00 & 0.815 & 34.13 & 23.76 & 0.025 \\
\hline
\end{tabular}

$\mathrm{P}^{\star}$ : professional; $\mathrm{L}^{\star}$ : layperson.

is bilateral symmetry and the human eye is sensitive to differences in the two sides of paired structures [36]. Strict observation of hard and fast rules should, however, not blind us to the subtle uncertainty expressed by Picasso "art is not the appreciation of a canon of beauty but what instinct and the brain can conceive of outside the canon" [37]. Cleft lip surgeons must thus continue to be perfectionists and be willing to work in fractions of millimeters for the best possible results $[9,38]$.

\section{Conclusion}

Reconstruction of the upper lip and nostrils requires a thoughtful combination of art and science. We have contributed towards the science by describing the morphology of the philtral columns and nostrils and the aesthetic preferences in Nigerian children. We found that the triangular shaped philtral column is the commonest in boys and girls. There are significant age differences in the aesthetic rankings of philtral columns and nostril shapes. However, the aesthetic preferences are similar for professional status and gender. We hope that the results of our study and reconstructive surgery will intersect at a point to treat disfigurements of the upper lip-nose subunit in Nigerian children successfully.

\section{References}

[1] M. G. Bozkir, P. Karakas, and Ö. Oguz, "Vertical and horizontal neoclassical facial canons in Turkish young adults," Surgical and Radiologic Anatomy, vol. 26, no. 3, pp. 212-219, 2004.

[2] R. S. Gosla, V. Devarakonda, and R. R. Reddy, "Assessment of nostril symmetry after primary cleft rhinoplasty in patients with complete unilateral cleft lip and palate," Journal of CranioMaxillofacial Surgery, vol. 41, pp. 147-152, 2013.

[3] V. P. Sharma, H. Bella, M. M. Cadier, R. W. Pigott, T. E. E. Goodacre, and B. M. Richard, "Outcomes in facial aesthetics in cleft lip and palate surgery: a systematic review," Journal of
Plastic, Reconstructive \& Aesthetic Surgery, vol. 65, pp. 12331245, 2012.

[4] X. He, B. Shi, M. Kamdar, Q. Zheng, S. Li, and Y. Wang, "Development of a method for rating nasal appearance after cleft lip repair," Journal of Plastic, Reconstructive and Aesthetic Surgery, vol. 62, no. 11, pp. 1437-1441, 2009.

[5] B. C. Cho and B. S. Baik, "Formation of philtral column using vertical interdigitation of orbicularis oris muscle flaps in secondary cleft lip," Plastic and Reconstructive Surgery, vol. 106, no. 5, pp. 980-986, 2000.

[6] S. W. Kim, M. Oh, J. L. Park, A. K. Oh, and C. G. Park, "Functional reconstruction of the philtral ridge and dimple in the repaired cleft lip," Journal of Craniofacial Surgery, vol. 18, no. 6, pp. 1343-1348, 2007.

[7] N. Kishi, S. Tanaka, S. Iida, and M. Kogo, "The morphological features and developmental changes of the philtral dimple: a guide to surgical intervention in cases of cleft lip," Journal of Cranio-Maxillofacial Surgery, vol. 40, no. 3, pp. 215-222, 2012.

[8] S. O. P. Hofer and M. A. M. Mureau, "Improving outcomes in aesthetic facial reconstruction," Perioperative Nursing Clinics, vol. 6, no. 2, pp. 147-158, 2011.

[9] I. Ercan, A. Etoz, I. Guney et al., "Statistical shape analysis of nose in Turkish young adults," Journal of Craniofacial Surgery, vol. 18, no. 1, pp. 219-224, 2007.

[10] P. N. Broer, S. Buonocore, A. Morillas et al., "Nasal aesthetics: a cross-cultural analysis," Plastic and Reconstructive Surgery, vol. 130, pp. 843e-850e, 2012.

[11] F. Vegter and J. J. Hage, "Clinical anthropometry and canons of the face in historical perspective," Plastic and Reconstructive Surgery, vol. 106, no. 5, pp. 1090-1096, 2000.

[12] J. P. Porter, "The average African American male face: an anthropometric analysis," Archives of Facial Plastic Surgery, vol. 6, no. 2, pp. 78-81, 2004.

[13] A. Mori, T. Nakajima, T. Kaneko, H. Sakuma, and Y. Aoki, "Analysis of 109 Japanese children's lip and nose shapes using 3-dimensional digitizer," British Journal of Plastic Surgery, vol. 58, no. 3, pp. 318-329, 2005. 
[14] B. Khandekar, S. Srinivasan, N. Mokal, and M. R. Thatte, "Anthropometric analysis of lip-nose complex in Indian population," Indian Journal of Plastic Surgery, vol. 38, no. 2, pp. 128131, 2005.

[15] B. Q. Etöz, A. Etöz, and I. Ercan, "Nasal shapes and related differences in nostril forms: a morphometric analysis in young adults," Journal of Craniofacial Surgery, vol. 19, no. 5, pp. 14021408, 2008.

[16] J. A. Biller and D. W. Kim, "A contemporary assessment of facial aesthetic preferences," Archives of Facial Plastic Surgery, vol. 11, no. 2, pp. 91-97, 2009.

[17] L. G. Farkas, T. A. Hreczko, and C. K. Deutsch, "Objective assessment of standard nostril types-a morphometric study," Annals of Plastic Surgery, vol. 11, no. 5, pp. 381-389, 1983.

[18] T. Yamada, Y. Mori, K. Minami, K. Mishima, and Y. Tsukamoto, "Three-dimensional analysis of facial morphology in normal Japanese children as control data for cleft surgery," The Cleft Palate-Craniofacial Journal, vol. 39, pp. 517-526, 2002.

[19] C.-S. Chang, Y. C. Por, E. J.-W. Liou, C.-J. Chang, P. K.-T. Chen, and M. S. Noordhoff, "Long-term comparison of four techniques for obtaining nasal symmetry in unilateral complete cleft lip patients: a single surgeon's experience," Plastic and Reconstructive Surgery, vol. 126, no. 4, pp. 1276-1284, 2010.

[20] K. A. Russell, S. D. Waldman, B. Tompson, and J. M. Lee, "Nasal morphology and shape parameters as predictors of nasal esthetics in individuals with complete unilateral cleft lip and palate," The Cleft Palate-Craniofacial Journal, vol. 38, pp. 476485, 2001.

[21] N. Kishi, S. Tanaka, S. Iida, and M. Kogo, "Comprehensive evaluation of three-dimensional philtral morphology," Journal of Craniofacial Surgery, vol. 22, no. 5, pp. 1606-1611, 2011.

[22] T. Yamada, Y. Mori, K. Minami, K. Mishima, T. Sugahara, and M. Sakuda, "Computer aided three-dimensional analysis of nostril forms: application in normal and operated cleft lip patients," Journal of Cranio-Maxillofacial Surgery, vol. 27, no. 6, pp. 345-353, 1999.

[23] P. Nechala, J. Mahoney, and L. G. Farkas, "Digital twodimensional photogrammetry: a comparison of three techniques of obtaining digital photographs," Plastic and Reconstructive Surgery, vol. 103, no. 7, pp. 1819-1825, 1999.

[24] V. F. Ferrario, C. Sforza, G. Serrao, V. Ciusa, and C. Dellavia, "Growth and aging of facial soft tissues: a computerized threedimensional mesh diagram analysis," Clinical Anatomy, vol. 16, no. 5, pp. 420-433, 2003.

[25] T.-S. Hwang and H.-S. Kang, "Morphometry of nasal bases and nostrils in Koreans," Annals of Anatomy, vol. 185, no. 2, pp. 189193, 2003.

[26] F. A. Ofodile, F. J. Bokhari, C. Ellis, and W. E. Matory Jr., "The black American nose," Annals of Plastic Surgery, vol. 31, no. 3, pp. 209-219, 1993.

[27] L.-J. Lo, F.-H. Wong, S. Mardini, Y.-R. Chen, and M. S. Noordhoff, "Assessment of bilateral cleft lip nose deformity: a comparison of results as judged by cleft surgeons and laypersons," Plastic and Reconstructive Surgery, vol. 110, no. 3, pp. 733$738,2002$.

[28] J. Kunjur, T. Sabesan, and V. Ilankovan, "Anthropometric analysis of eyebrows and eyelids: an inter-racial study," British Journal of Oral and Maxillofacial Surgery, vol. 44, no. 2, pp. 8993, 2006.

[29] N. S. Park, J. H. Park, M. Bayome, S. S. Mo, Y. Kim, and Y. A. Kook, "An evaluation of preferred lip positions according to different age groups," International Journal of Oral and Maxillofacial Surgery, vol. 42, 5, pp. 637-642, 2012.

[30] O. Adetayo, R. Ford, and M. Martin, "Africa has unique and urgent barriers to cleft care: lessons from practitioners at the Pan-African Congress on Cleft Lip and Palate," The Pan African Medical Journal, vol. 12, article 15, 2012.

[31] S. Stal, R. H. Brown, S. Higuera et al., "Fifty years of the millard rotation-advancement: looking back and moving forward," Plastic and Reconstructive Surgery, vol. 123, no. 4, pp. 1364-1377, 2009.

[32] N. Chaithanyaa, K. K. Rai, H. R. Shivakumar, and A. Upasi, "Evaluation of the outcome of secondary rhinoplasty in cleft lip and palate patients," Journal of Plastic, Reconstructive and Aesthetic Surgery, vol. 64, no. 1, pp. 27-33, 2011.

[33] J. S. Garfinkle, T. W. King, B. H. Grayson, L. E. Brecht, and C. B. Cutting, "A 12-year anthropometric evaluation of the nose in bilateral cleft lip-cleft palate patients following nasoalveolar molding and cutting bilateral cleft lip and nose reconstruction," Plastic and Reconstructive Surgery, vol. 127, no. 4, pp. 1659-1667, 2011.

[34] D. M. Fisher, R. Tse, and J. R. Marcus, "Objective measurements for grading the primary unilateral cleft lip nasal deformity," Plastic and Reconstructive Surgery, vol. 122, no. 3, pp. 874-880, 2008.

[35] E. Christofides, A. Potgieter, and L. Chait, "A long term subjective and objective assessment of the scar in unilateral cleft lip repairs using the Millard technique without revisional surgery," Journal of Plastic, Reconstructive and Aesthetic Surgery, vol. 59, no. 4, pp. 380-386, 2006.

[36] M. F. Grasseschi, "Minimal scar repair of unilateral cleft lip," Plastic and Reconstructive Surgery, vol. 125, no. 2, pp. 620-628, 2010.

[37] L. Ousehal, L. Lazrak, I. Serrhini, and F. Elquars, "Evaluation of facial esthetics by a panel of professionals and a lay panel," International Orthodontics, vol. 9, no. 2, pp. 224-234, 2011.

[38] C. J. Boorer, D. C. Cho, V. S. Vijayasekaran, and D. M. Fisher, "Presurgical unilateral cleft lip anthropometrics: implications for the choice of repair technique," Plastic and Reconstructive Surgery, vol. 127, no. 2, pp. 774-780, 2011. 


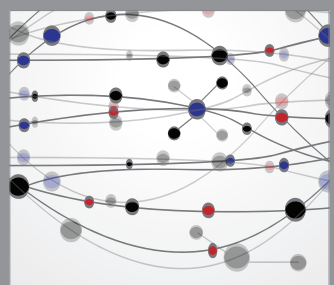

The Scientific World Journal
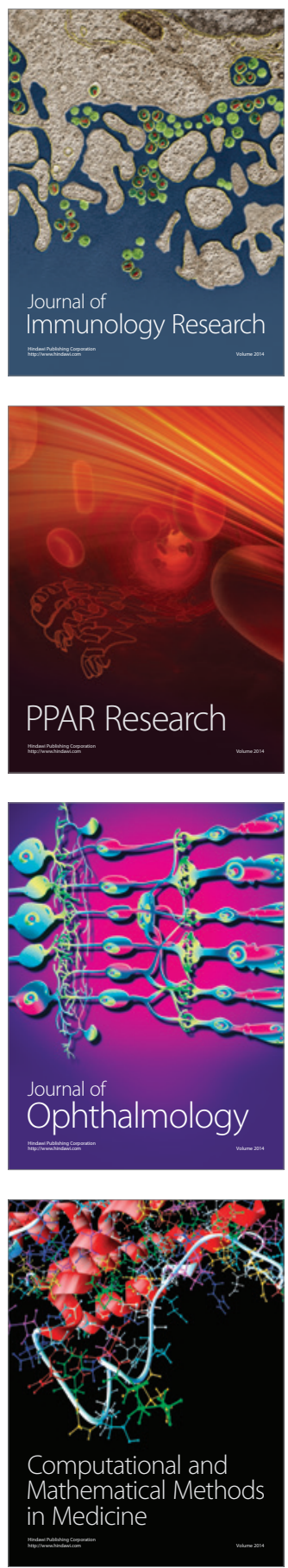

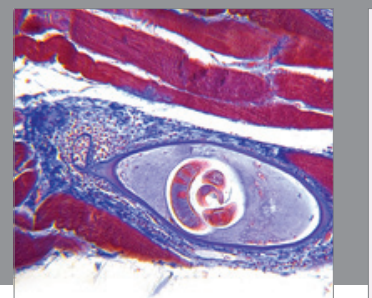

Gastroenterology

Research and Practice
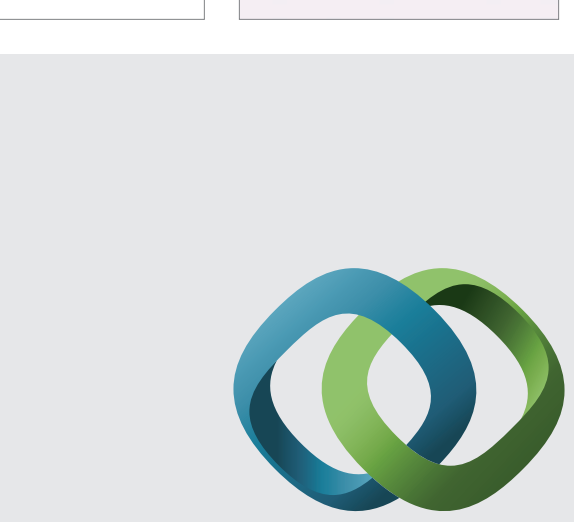

\section{Hindawi}

Submit your manuscripts at

http://www.hindawi.com
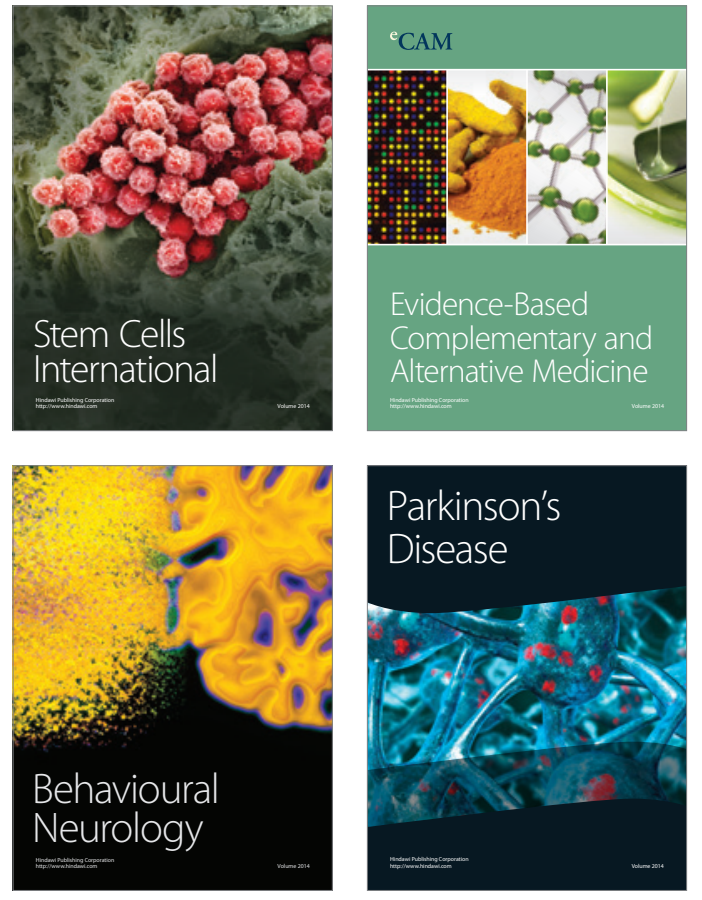
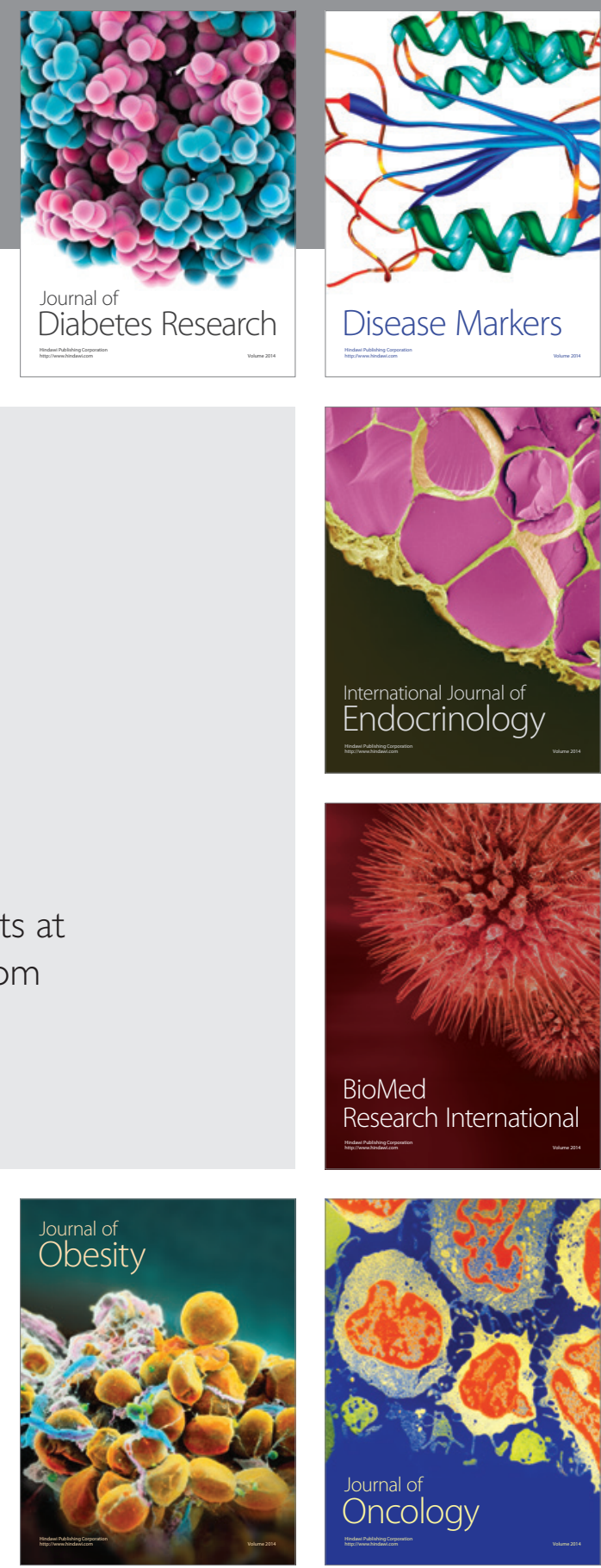

Disease Markers
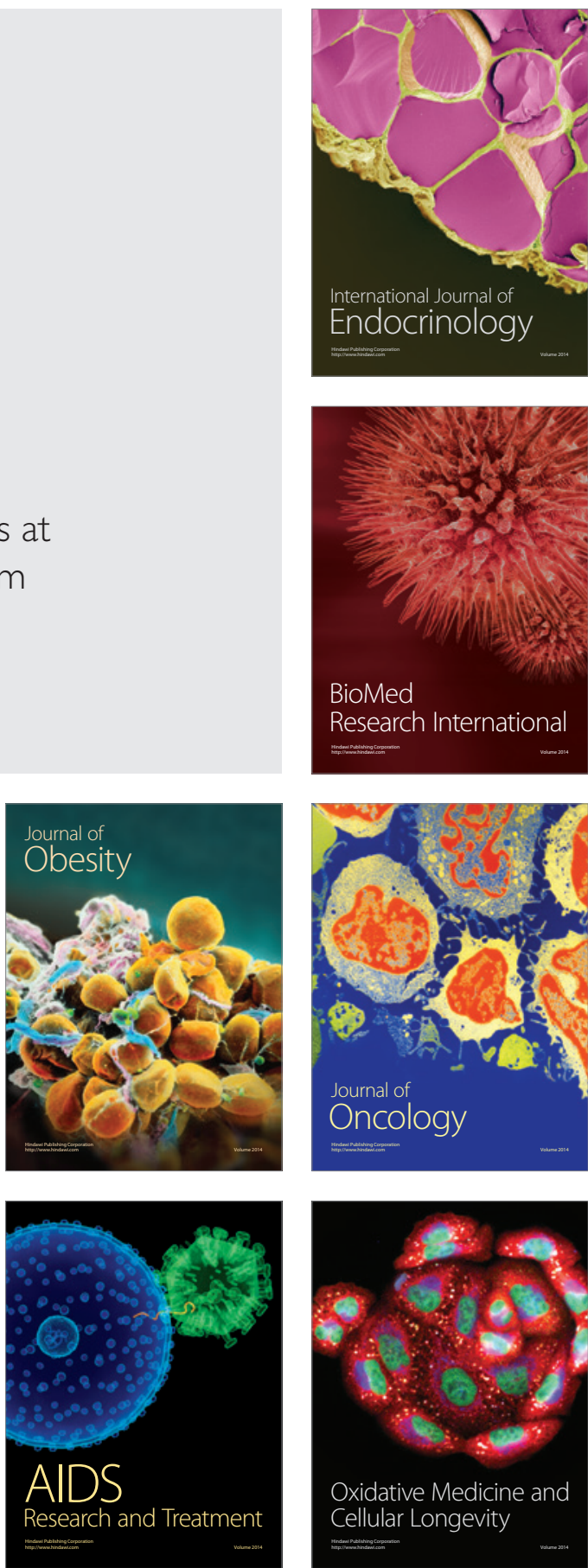